\title{
LET THE GAME BEGIN: ERGODIC AS AN APPROACH FOR VIDEO GAME TRANSLATION
}

\author{
SF. Lukfianka Sanjaya Purnama, SF. Luthfie Arguby Purnomo, Dyah Nugrahani \\ IAIN Surakarta \\ sastrainggrisiainska1@gmail.com
}

\begin{abstract}
This paper attempts to propose ergodic as an approach for video game translation. The word approach here refers to an approach for translation products and to an approach for the translation process. The steps to formulate ergodic as an approach are first, Aarseth'sergodic literature is reviewed to elicit a basis for comprehension toward its relationship with video games and video game translation Secondly, taking the translation of Electronic Arts 'Need for Speed: Own the City, Midway's Mortal Kombat: Unchained, and Konami's Metal Gear Solid, ergodic based approach for video game translation is formulated. The formulation signifies that ergodic, as an approach for video game translation, revolves around the treatment of video games as a cybertext from which scriptons, textons, and traversal functions as the configurative mechanism influence the selection of translation strategies and the transferability of variables and traversal function, game aesthetics, and ludus and narrative of the games. The challenges countered when treating video games as a cybertext are the necessities for the translators to convey anamorphosis, mechanical and narrative hidden meaning of the analyzed frame, to consider the textonomy of the games, and at the same time to concern on GILT (Globalization, Internationalization, Localization, and Translation).
\end{abstract}

Keywords: Ergodic, Translation Approach, Video Game Translation, Textonomy, Anamorphosis

\section{INTRODUCTION}

Approaches designed for video game translation revolve either around ludological and narratological perspectives, or the combination of both as formulated by Esselink (2000), by Mangiron and O'Hagan's transcreation (2006), by Bernal-Merino (2009) and by Costales (2012). Either approaches applied, they share, though they do not state it explicitly, similar perspectives in the way that they treat video games as a cybertext, as an ergodic literature.

Ergodic derives from Greek words ergon which means work and hodos which means path (Aarseth, 1997) from which ergodic literature, a type of literature requiring nontrivial efforts to allow the reader to traverse the text (1997), emerges and from which type of discourse whose signs emerges a path produced by a non-trivial element of work like I Ching, hypertext, interactive media, computer games, automated poetry generators, and Multiuser Discourse 
(MUD's) (Aarseth in Rush, 2005). From the aforementioned etymological meaning and definition, ergodic denotes indexical, benefactive, and configurative relationships. Indexical relationship emerges, for instance, when video games, the focus of this article, hints the players to solve some puzzles or presents the players some tutorials to solve the puzzles. It implies that when the players solve the puzzles either from hints or tutorials, contiguity and factoriality, part/whole relationships (Trifonas, 2015), are eminent.

This indexical relationship is selected based on benefactive function from which benefactive relationship between the games and the players in the embodiment of winning or losing surfaces. The choices to solve the puzzles as implied by indexical relationship and the selection toward the choices as signified by benefactive relationship are mechanized through the employment of configurative relationship. When the players, for instance, decides to take the hint as a resolve for their puzzles, they automatically and axiomatically proceed to perform configuration upon the games in the manner of procedurality, to respond to the mechanics of the game (Bogost, 2007), or of instrumentality, to exercise procedure-free responses (Sicart, 2011).This ergodict triangular relationship is embodied through scriptons, textons, and traversal functions.

Scriptons are strings appearing to the readers, textons as existing in the text, and traversal functions are the mechanism by which scriptons are revealed or generated from textons and presented to the user of the text (Aarseth, 1997). The strings mentioned in the definition refer to linguistic units delivered by programming language.The connection between scriptons, textons, and traversal function with the aforementioned triangular relationship is illustrated as follow:

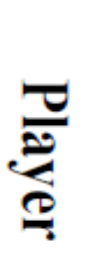

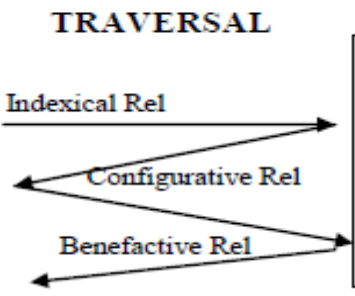

FUNCTION
TRAVERSAL

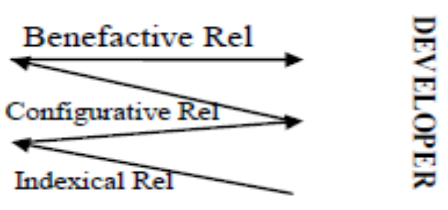

FUNCTION

Players, when immersing into the games, focus on the scriptons displayed through the existence of textons previously designed by the developers. The different focus the players and 
the developers have trigger different initiation from the triangular relationship. The players experience indexical relationship, first, before they engage in the configurative one. In the phase of configurative relationship, the players respond the game world through the avatars they are playing by mechanically executing either procedural or instrumental configuration. This actions by the players defining the configurative relationship are what Rush terms as ergodic-direct (2005) from which ergodic-represented, the result of the user action (2005), emanates to evoke a benefactive relationship. This relationship is eventually evoked to the players in the visual representation of winning and losing. A different causal flow occurs on the developer side. On the developer perspectives, the focus is directed to the textons to which the developers compute programming language from which linguistic units are blended.

Through the textons transcribed into the scriptons, the developers attempt to deliver indexical relationship to the players. The designed textons and scriptons, in game for instance, whether they are in ASCII or Unicode, also contain configurative aspects from which the indexical relationship is constructed via game mechanics. Through this game mechanics, the expectation the designers have on benefactive relationship the players are expected to experience is embodied.

The implication acquired from the aforementioned relations between the triangular relationship and the ergodic variables is that any text appearing from cybertext media generates mechanical impacts. These mechanical impacts are what Frasca highlights as ludology, the science of play, (1999). In the perspectives of video games, ludology attempts to place video games as games not as another form of narrative as what narratologists claim (2007) and video games as rule-based system (Juul, 2005). These claims by ludologists imply that video games are mechanical in nature and thereby any elements video games possess emanate and evoke mechanical impacts to the game worlds, the avatars, and the players from which the ergodic triangular relationship and their connection to scriptons, textons, and traversal functions emerge. This mechanical implication observed from its traversal function is realized into seven variables:

\section{Dynamics}


In a static text the scriptons are constant; in a dynamic text the contents of scriptons may change while the number of textons remains fixed (intratextonic dynamics, or ITD), or the number (and content) of textons may vary as well (textonic dynamics, or TTD)

\section{Determinability}

This variable concerns the stability of the traversal function; a text is determinate if the adjacent scriptons of every scripton are always the same; if not, the text is indeterminate.

\section{Transiency}

If the mere passing of the user's time causes scriptons to appear, the text is transient; if not, it is intransient.

\section{Perspectives}

If the text requires the user to play a strategic role as a character in the world described by the text, then the text's perspective is personal; if not, then it is impersonal.

\section{Access}

If all scriptons of the text are readily available to the user at all times, then the text is random access (typically the codex); if not, then access is controlled.

\section{Linking}

A text may be organized by explicit links for the userto follow, conditional links that can only be followed if certain conditions are met, or by none of these (no links).

\section{User Functions}

Besides the interpretative function of the user, which is present in all texts, the use of some texts may be described in terms of additional functions: the explorative function, in which the user must decide which path to take, and the configurative function, in which scriptons are in part chosen or created by the user. (Aarseth, 1997). Either texts the cybertext is categorized into, they revolve around the indexical, configurative, and benefactive relationships between the games and the players. This ergodic triangular relationship is differently and variedly responded by the players depending on the text types they engage. In the perspectives of video game translation, the focus of analysis revolves around the transferability of the text variables from source language to the target one.

\section{Ergodic, Video Game Translation, and the Problems of Transferability}

Munday (2008) places video game translation as new media requiring new directions in the manner of functionalist approach and thereby by functionalist approach, it indicates that the translation is of specialized translation (Nord, 2006) which requires a special treatment to 
approach it. This functionality signifies the necessity to treat the product of translation as functional in itself and functional to itself since being functional involves being functional to whom functionality applies and from whom functionality derives. In the perspectives of video games, the to-whom variables, their gaming activities. Meanwhile the from-whom variables refer to the presented problems in the games and the interactions between the players with the games in the scope of HCI (Human-Computer Interaction). It further suggests that in the ergodic perspectives of cyber-text, functionalist approach for video games denotes the significance of ergodic triangular relationship and the ergodic variables from which texts are classified.

\section{Ergodic and the Transferability of Variables and Traversal Function}

The focus of implementing ergodic approach in translation studies in the domain of video game translation is to reveal whether variable shifts and shifts on traversal function occur when a text is translated. To reveal the shifts on ergodic variables, mechanical comprehension toward each variable should be considered. In the perspectives of video game translation, the steps taken to approach video game translationare to describe the assets of the video games. Assets range from in-game text, art, audio, cinematics, and printed assets (Chandler (2005) in Mangiron and O'Hagan, 2013). In ergodic-textonomy, the assets have features differentiating each asset from the others.

Table 1. Assets and Textonomy Typology

\begin{tabular}{|l|l|l|l|l|}
\hline Assets & Features & $\begin{array}{l}\text { Traversal } \\
\text { Function }\end{array}$ & Textonomy & $\begin{array}{l}\text { Ideology of } \\
\text { Influence }\end{array}$ \\
\hline In-Game & OST (On Screen & Textonic & Intratextonic & Anamorphosis \\
& $\begin{array}{l}\text { Text), UI (User } \\
\text { Interface), }\end{array}$ & $\begin{array}{l}\text { Configurative } \\
\text { Explorative }\end{array}$ & $\begin{array}{l}\text { Dynamics (ITD) } \\
\text { Textonic }\end{array}$ & Metamorphosis \\
& Narrative and & Interpretative & $\begin{array}{l}\text { Dynamics (TTD) } \\
\text { Static }\end{array}$ & \\
& Descriptive & & Stic & \\
& Passages, & & & \\
& Dialogue, NPC's & & & Anamorphosis \\
& Conversation & & Metamorphosis \\
Art & Graphics and & Textonic & ITD & Anamorphosis \\
& Images & Configurative & TTD & Metamorphosis \\
& Sudio & Interpretative & Static & \\
& Songs, Cutscenes & Textonic & ITD & \\
& & Configurative & TTD & \\
& & Interpretative & Static & \\
& & & & \\
\hline
\end{tabular}




\begin{tabular}{|lllll|}
\hline Cinematics & Cutscenes & $\begin{array}{l}\text { Textonic } \\
\text { Configurative } \\
\text { Explorative } \\
\text { Interpretative }\end{array}$ & $\begin{array}{l}\text { TTD } \\
\text { ITD } \\
\text { Printed Assets }\end{array}$ & $\begin{array}{l}\text { Anamorphosis } \\
\text { Metamorphosis }\end{array}$ \\
& $\begin{array}{l}\text { Guide, Sketch, } \\
\text { Biography }\end{array}$ & Interpretative & Static & Metamorphosis \\
\hline
\end{tabular}

(Adapted from Chandler (2005) in Mangiron and O’Hagan, 2013)

Dynamics refers to the number and format of textons and scriptons. If the number of textons and scriptons share equality, the dynamics is static. If the textons are non-diegetic text based and so are the scriptons, the dynamics is static. If the number of textons is constant, but the number of scriptons is varied, the dynamics is intratextonic dynamics. If the textons are formatted in non-diegetic text, but the scriptons are in diegetic text, the dynamics is also intratextonic and vice versa. If the number of textons is varied and the number of scriptons is also varied, the dynamics is textonic. If the texton is in image and diegetic, and the scripton is in either of the format, the dynamics is textonic. Departing from the assumption that non-diegetic text, from the perspective of data processing, embeds technical and operational difficulties, it arrives to a comprehension that:

Table 2. Dynamics Variables

\begin{tabular}{|l|l|l|}
\hline Textonomy & Spatiality & Performativity \\
\hline Static & Definite & Singular \\
Intratextonic Dynamics & Indefinite & Plural \\
Textonic Dynamics & Indefinite & Plural \\
\hline
\end{tabular}

Definite spatiality provides a limited access to the textonomy and thereby the translators have to be selective in applying the linguistics units or images for their translation. In contrast, intratextonic and textonic dynamics enable the translators to access a susceptible amount of space for their translations but due to the existence of complex combination of non-diegetic and diegetic texts, the translators are required to execute a plural performativity, a multi tasking revolving around non-diegetic and diegetic textprocessing. On the other hand, static textonomy requires the translators to do a singular performativity: working on the diegetic s or images. 
Therefore, in the perspectives of video game translation, this dynamics is vulnerable to alter and thereby a shift might occur.

The understanding on textonomy and text type contributes to the translation selection strategy from which considerations on the ideologies of anamorphosis and metamorphosis are taken. The following example from might help clarify the statement:

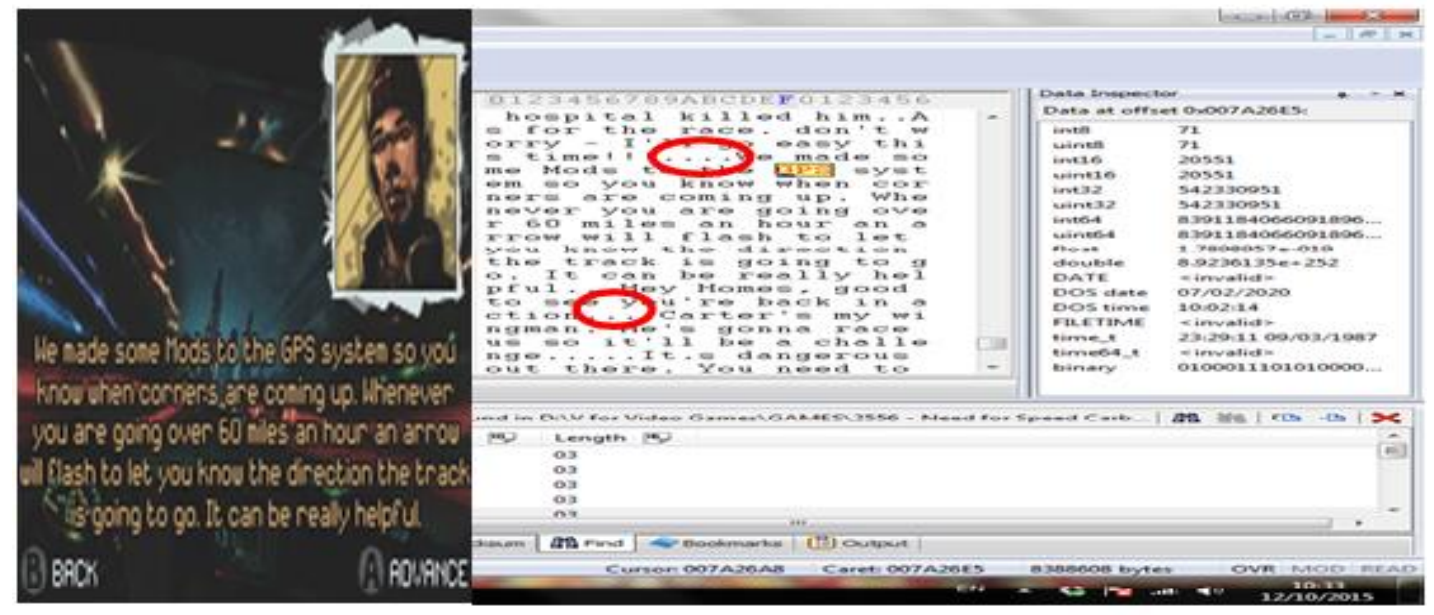

Figurel Need for Speed Carbon: Own the City

The textons from Need for Speed Carbon: Own the City are of intratextonic as the constant textons provide, as indicated by the circle, an opportunity for the scriptons to change though only for three spaced characters. The translators might utilize the opportunity to select the dictions from which anamorphosis ideology could be transferred. The anamorphosis ideology is noticeable from the implication of the frame demanding the players to check the GPS as they speed up exceeding 60 miles an hour.

This anamorphosis requires both procedural and instrumental configuration from the players. In the case of the racing game, the players are instructed to preserve their concentration to the track by examining the signal displayed in a flashing arrow. The followings are the translated version of the racing game by two different groups of translation with each group consisting of three members. The three members were taking the roles of translator, editor, and typesetter. The following translation is not intended to violate the copyright as the translation is 
intended purely for educational purposes. The following translation will indicate that intertextonic, though flexible for executing a rewriting on the textons, still has some limitations.

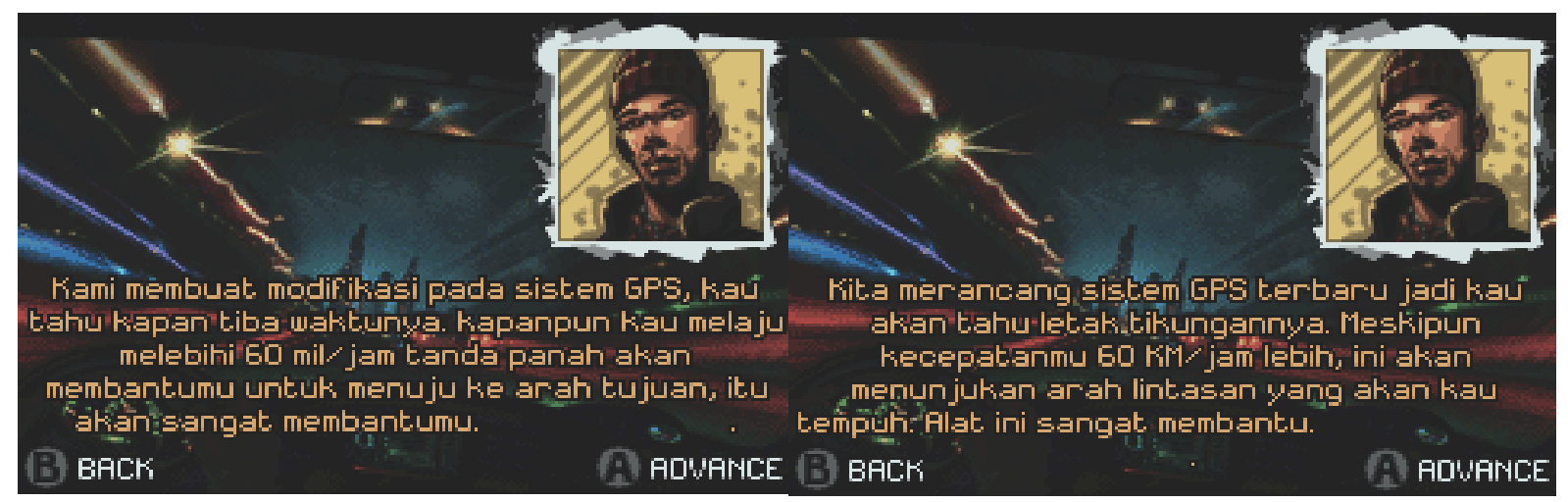

Figure 1 Indonesian version of Need for Speed Carbon: Own the City

The intertextonic characteristic the textons have in the aforementioned game evokes a flexible translation strategy selection. The changes on text display, as perceived from the above screenshots, indicate that the scriptons are varied and thereby signifying the intratextonic characteristics of the textons. In the case of the anamorphosis of the game, the left screenshot is able to transfer the configurative implication regarding with the emergence of an arrow shaped signal translated into 'tandapanah' while the right one does not cope the configuration optimally due to the absence of the translation of the word 'arrow'. Though the right screenshot misses the word 'arrow', it pertains 'corners' translated into 'tikungan' from which configurations from the players entail. Meanwhile, the left screenshot does not preserve 'corners' on their translation. It implies that inter-textonic characteristics of the textons are proven to be less beneficial when, as $\operatorname{Dietz}(200$, said about the requirement to be a video game translator the translation and computer ability are not of quality.

In the relation with translation techniques, the deletion employed on the word 'arrow' and 'corners' triggers significant impact on the holistic apprehension of the traversal function. The deletion ignites a traversal function shift from procedural/instrumental to instrumental configuration only. Four scriptons contributing to the emergence of traversal function are 
'corners', '60 miles an hour', 'arrow', and 'flash'. These four units suggest mechanical implication in the form of procedural and instrumental configuration. Procedural configuration emerges from:

acceleration $\mid$ if $|>60|$ corner $\mid$ arrow.sign | flash

acceleration $\mid$ if $|<60|$ corner $\mid$ arrow.sign | not.flash

The above logical string suggests that a configuration from the players will occur procedurally as suggested from the scriptons. The players have to hit the acceleration button to hit over 60 miles an hour to evoke the emergence of the flashing arrow. The absence of a scripton, as pointed out by the string above, signifies the reduction on the completeness of a sequence to make an event happen. This condition is what Rehak terms as suture, a condition by which spectators are 'stitched into' the signifying chain through edits that articulate a plentitude of observed space to an observing character (in Isigan, 2013). In the case of the aforementioned translation, the problem of being 'stitched into' occurs when the translation technique of deletion is applied and thereby ludological observation by the players is assumed to be reduced.

\section{Ergodic and the Transferability of Game Aesthetics}

Aesthetics in video games is concerned on the audiovisual style the games employ (Jarvinen, 2002). The styles oscillate around three elements: (1) space/environment (2) different objects, and (3) symbols (Jarvinen, 2002). In the case of Need for Speed Carbon: Own the City translation, the aesthetic element experiencing a shift is on the symbol. The influence of translation techniques is assumed to trigger an impact on the on screen text display of the game. As perceived from the game screenshots, the text display experiences a technical shift of presentation.

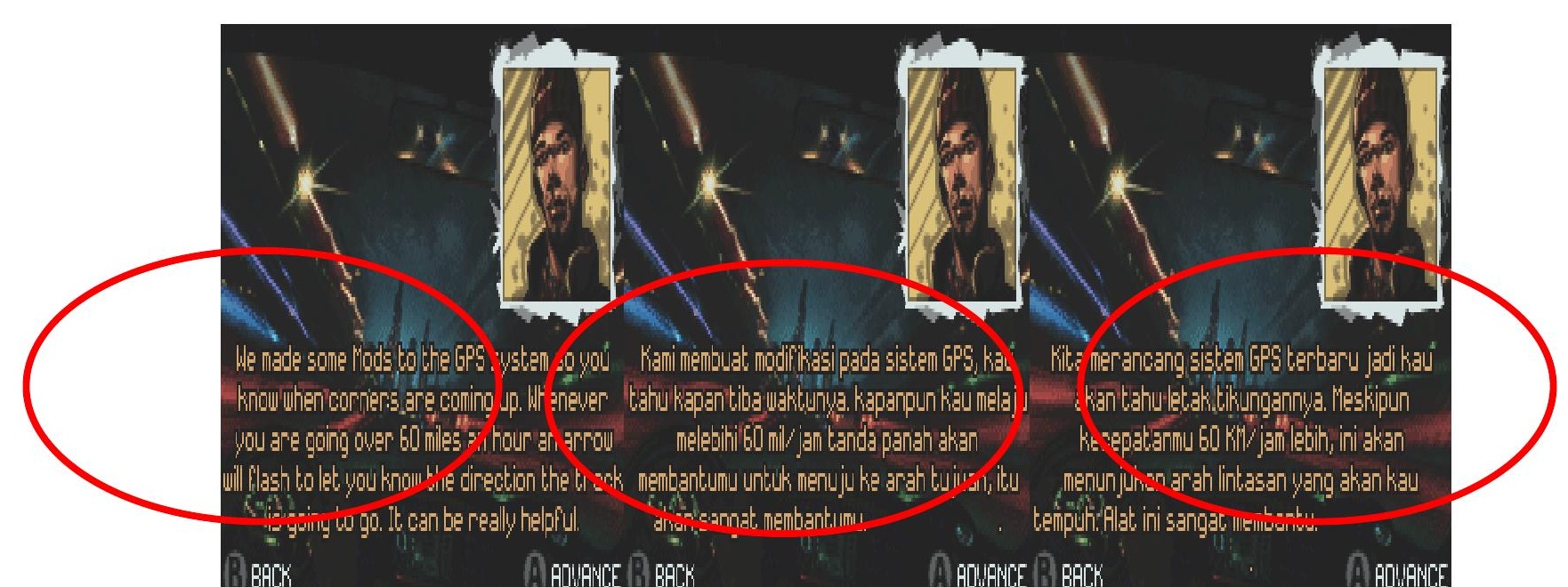




\section{Figure2 Different text display}

The jumbled structure of the translated versions indicate that the translation focuses mainly on transferring the message by examining the probable space intratextonic dynamics offers.From aesthetics viewpoint, this jumbled structure is assumed to contribute to the shift of game experience knowing that transferring a similar game experience is what game localization (and translation) prioritizes to convey (O'Hagan, 2009). In the case of the dynamics, the flexibility the dynamics offers is not yet considered for aesthetic function of the game as the flexibility itself is still character restricted. This condition is implied by Alexander O'Smith, the translator of various Square Enix's games. He said that there were often strict character limits for UI elements in the English translation, so diving straight into dialog and narrative text could be dangerous when the translators eventually realized none of the UI terms they wanted to use there would actually fit (in Jayemanne, 2009). It implies that the applied translation techniques will, in a direct manner, influence the graph structure of the text in frame. It further suggests also that the knowledge and skill of restructuring in translation studies should touch the domain of graphology and typeface restructuring since aesthetics influence the physical form of play, sensory relationship between the players and the games (Myers (2009) in Zimmerman, Perron and Wolf, 2009). Therefore, translation techniques, traversal function and game aesthetics (audiovisual style) construct a causal relationship.

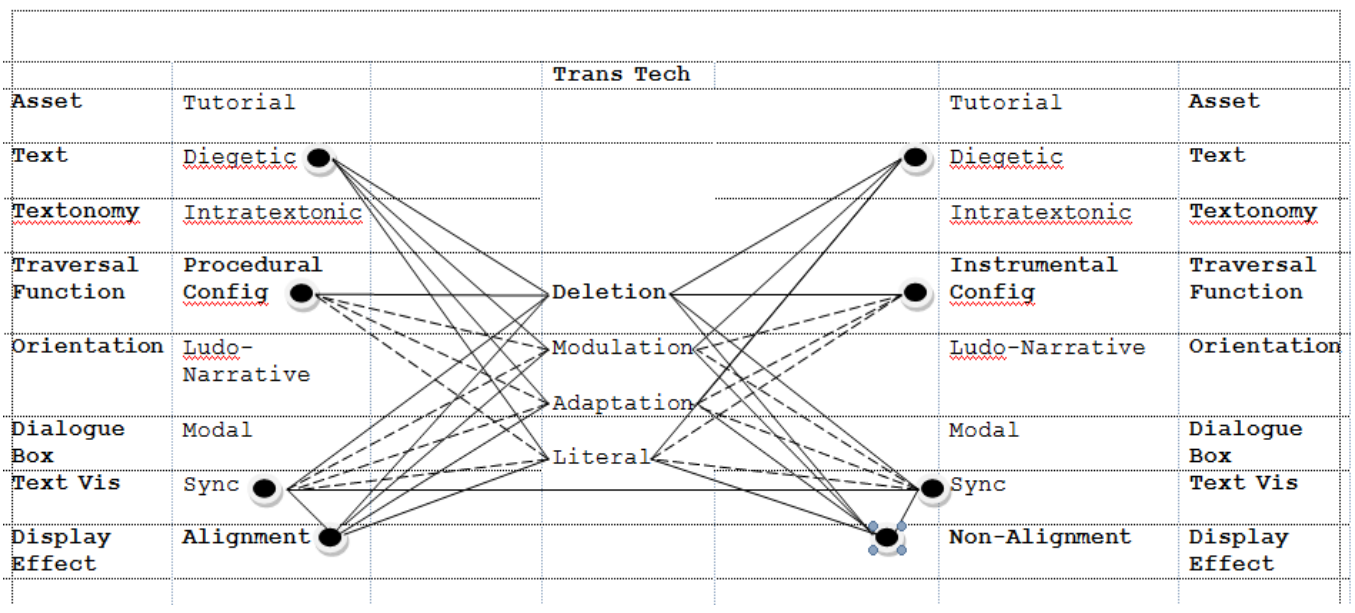

Figure3 The influence of translation techniques in traversal function and game aesthetics 
Asset refers to the analyzed game element, Text to whether the format is diegetic (linguistic unit) or non-diegetic (image), Textonomy, as discussed before, to the dynamicity of a text, Traversal Function to the method the players respond to the text, Orientation to whether the asset has only ludic, narrative, or both elements, Dialogue Box to the type of box on which the textons appear as scriptons to the players, Text Visualization to the techniques information is visualized, and Display Effect to aesthetic effects regarding with the scripton appearance. As seen from Figure 4 of which the construction is based on the translated version of Need for Speed Carbon: Own the City, deletion applied on a diegetic text triggers a shift on the traversal function of the frame and the alignment as the display effect from which symbol element of game aesthetics is observed. If the text had been shifted from diegetic to non-diegetic, the nonalignment display effect would have not occurred and thereby the game aesthetics on symbol would have been preserved. Non-diegetic text, though requiring plural performativity, could be beneficial for preserving game aestheticsin the translation process if utilized optimally. One of the examples is the non-diegetic alteration in Capcom's Mighty Final Fight:

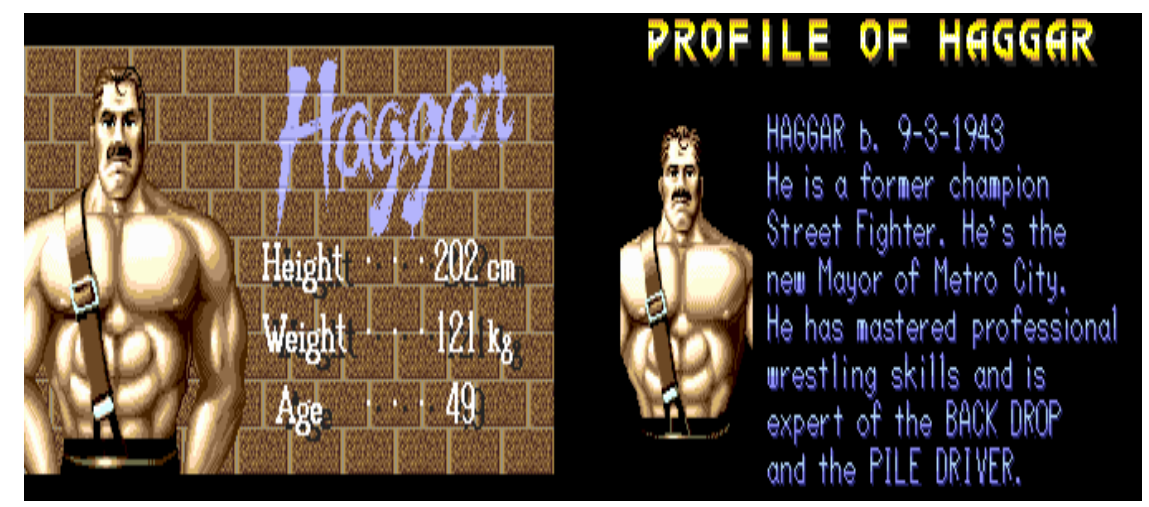

Figure 4 Non-Diegetic to Non-Diegetic with diegetic style

The reason of violence is behind the shift of non-diegetic text from the Japanese version to North American version on the profile of Haggar (Purnomo and Purnama, 2013). The nondiegetic text of the North American version, as seen from the screenshots, is able to visualize more information about the character. This situation indicates that non-diegetic, to some extent, is flexible to be utilized to cover diegetic information. It further suggests that plural performativity of the intratextonic and textonic dynamics is not a hindrance to convey the message intended to deliver. In the perspectives of translation techniques, the above case reflects 
that the translation technique applied is amplification. In ergodic perspectives, the question is whether the amplification occurs on the information given,on the data used, or both. By the amplification of information refers to the addition of new information not found on the source language. By the amplification of data implies that any texton addition triggers the addition of certain amount of space from which the amount of data inclines. This condition suggests that any selected translation techniques will have any consequence on the inclination of the data usage from which production cost might experience a hike.

Other translation techniques as seen from Figure 4 denote that their relationship with traversal function and game aesthetics still requires a close examination because modulation, adaptation, and literal are not conscientiously observable in the term of character number impact. In the perspectives of video game translation as a restrictive translation (Mangiron and O'Hagan, 2006), it is assumed that distinctive translation techniques possess spatiality in terms of character number. Description, Amplification, Linguistic Amplification, and Substitution might convey a larger space as they have magnification function in which new information is added for the clarity of meaning. Meanwhile Reduction, Deletion, and Linguistic Compression are assumed to trigger a smaller space as they have simplification function in which the information is reduced, deleted, and compressed. On the other hand, Adaptation, Borrowing, Discursive Creation, Established Equivalent, Literal, Modulation, Calque, Transposition, Variation are paradoxical as they are relative in generating the character number. Departing from this assumption, translation techniques, in video game translation, contribute to any ergodic elements and variables involving character numbers. In the case of game aesthetics, the translation techniques have a role in the shift of game aesthetics.

\section{Ergodic and the Transferability of Ludus and Narrative of Video Games}

Ludus, play in English word, owes its fame from Homo Ludens, a term introduced by Huizinga (1944) to refer to men as playful creatures. In the context of video games, ludusis studied by ludology, the science of play (Frasca, 2007), to refer to positioning video games as system of play not as a system of narrative (Juul, 2015) while narratology, the study of narrative (Bal, 2009), remarks that video games are a narrative which takes a different form like movies (Simons, 2007). Due to its position as a game system, ludus revolves aroundthe studies on game 
mechanics from which games pertain their function as a system. This game mechanics is one of the ludology principles video games have:

1. Games should be considered as systems, with elements interacting between each other within certain boundaries.

2. Games involve a conflict, which means that players will have to face some sort of challenge. This conflict is artificial in the sense that it is apart from real life.

3. Games are defined by rules. Rules are what delimit both the player's actions and the system's characteristics.

4. Games generate a quantifiable outcome. This can be a score or simply a judgment (winning or losing.). (Simon, 2007).

In the context of video games, ludus and narrative are ergodically diffused to suggest the emergence of anamorphosis, hidden meaning (Aarseth, 1997). This anamorphosis is vividly reflected from video game elements configuratively operated. They are pre-battle dialogue (PBD), command list, skill/ability, job, and equipment. One of the examples is from Metal Gear Solid
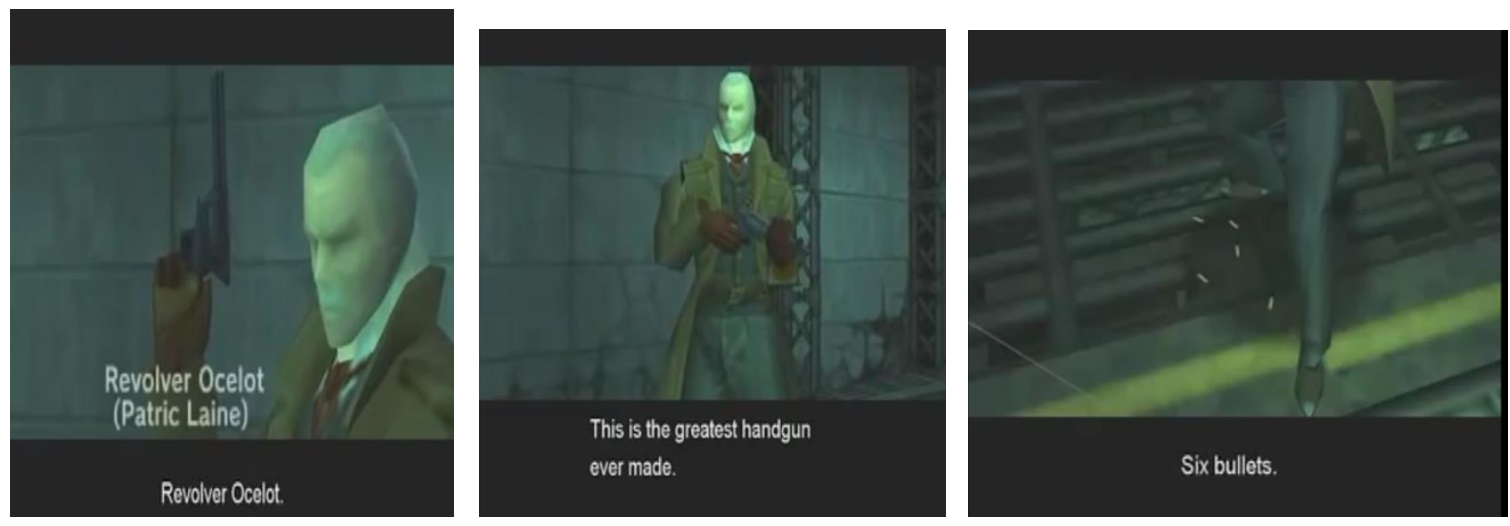

Figure 5 Revolver Ocelot and his Colt Single Action Army

The above screenshots occur in PBD (Pre-Battle Dialogue) between solid Snake and Revolver Ocelot. The word 'revolver' refers to his habit and skill in arming himself with a revolver. The emphasis that his arsenal is a revolver is strengthened by his statement about the arsenal which is a handgun and it has six bullets. The information about revolver, handgun, and six bullets, besides emphasizing in a narrative manner about the character of Revolver Ocelot, also signifies the ludus of the games from which the players could benefit from. The Ludus 
which is in the form of game mechanics suggests that revolver has six bullets only and thereby when Revolver Ocelot will reload a lot. The reloading condition opens the players to control Solid Snake, the main character, to shoot Revolver Ocelot. This anamorphosis, in the perspectives of video game translations, is a message the translators need to convey in their translation.

This anamorphosis, to some extent, opens a challenge to the translators if they are asked not only to perform translation but also localization. If the name of the character and the image of the gun are localized, the translators have to ensure themselves that the anamorphosis message is transferable. The problem of ludus and narrative transferability exposes a greater challenge when the anamorphosis resides on a word level such as in the name of an equipment as discussed in Purnomo (2015).

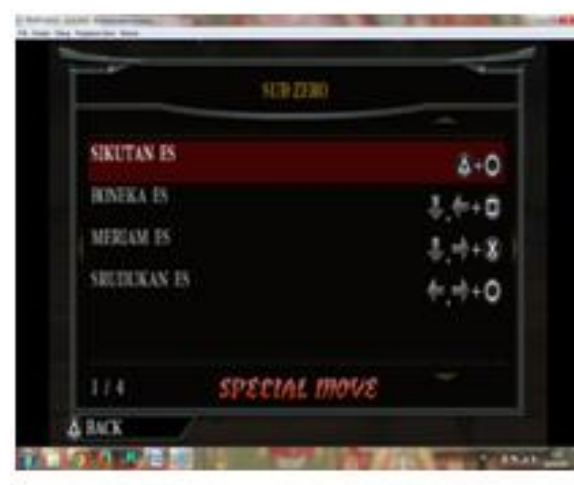

One of the examples regarding with this is the translation of Midway's Mortal Kombat: Unchained translated by two teams for educational purposes.

Sub Zero, the iconic character of the series, is a ninja with an ice based attack. His ice element, besides being reflected from the azure fighting gear he wears, is also reflected from mostly of the names of his moves. As seen from his source moves, middle screenshot, his special moves consist of Rib Breaker, Ice Clone, Freeze Ball, and Cold Shoulder. Each name of the moves is either the connotation or the denotation of the movements received by the viewers. Freeze Ball, for instance, is a move in which Sub Zero bursts cold ball like energy, from which the name 'ball' is derived, to freeze his foes, from which the word 'freeze' comes from. Therefore, it implies Freeze Ball shares a linearity between the name and the visual movement. 
When Freeze Ball is translated into Meriam Es (Ice Cannon) and Bola Salju (Snow Ball), the linearity is diverted.

The former translation to which compensation is applied ignites non-linearity because Sub Zero does not use any cannon. The latter translation to which modulation is applied has a problem of non-linearity also because Sub Zero does not burst snow ball. From the perspectives of narrative, both translations pertain the iciness of Sub Zero and aesthetics alignment with Sub Zero's attributes. Meanwhile, from the perspectives of ludus, game mechanics, it might deteriorate the players in playing the game, to some extent, when the players rely on the preliminary knowledge they attempt to obtain from the move nam e. The two aforementioned cases signify that anamorphosis finds itself in the diffusion of the ludus and narrative of the games with meta cognition of the players as the traversal mode.

Another interesting finding is on Sub Zero's Cold Shoulder, a move in which Sub Zero attacks his enemy by sliding and forwarding his shoulder to hit the enemy. The first translation is Srudukan Es (Ice Ram) and the second one is Dorongan Es Maut (Deadly Ice Push). There are three similarities of the two translation versions. First is that they modulate the perspectives from an object, which creates an impact to a process, which creates an impact. Second, they modulate also in their translation of cold, which is the sensation one feels when touching something icy into es (ice), which is the source of cold. Third, they omit some words to maintain the spatial stability for the words. The pattern of omission is the same. They omit vocals. This happens due to, as discussed before, spatial problems textons have. For the case of second translation, it is not just only modulation but also discursive creation visible from the word maut (deadly). This discursive creation ignites an intriguing finding regarding with loss and gain. Instead of vocalizing Dorongan (push), the translator chose to add a word discursively to the translated move to emphasize the deadliness of the move.

It implies that, to some extent, stylistics and aesthetics of the move are the priorities the translator decides to maintain. Though stylistics and aesthetics of the game arrive to consideration, the translator fails to notice the aesthetics of the move in narrative sense. The phrase Cold Shoulder also refers to an English idiom meaning 'total ignorance'. This aesthetic 
value is primarily concerned on the narrative life of Sub Zero himself. Sub Zero's real name is Kuai Liang. His life is identical to the phrase Cold Shoulder as he lives his own life after his parents and brother are dead. People ignore his existence and he lives just for revenge. This aesthetic value in a narrative manner, though revealed hermeneutically, is an anamorphosis, which deserves an attention to the translator as it constructs a holistic relationship between the ludus and the narrative from which metamorphosis and anamorphosis are evoked.

\section{CONCLUSION}

Ergodic as an approach for video game translation revolves on the discussion of the transferability of variables and traversal functions, of game aesthetics, and of ludus and narrative of the games. The transferability of the three elements poses a problem revolving around scriptons and textons possessing a close relationship with characters and their number. The problem also hails from the existence of anamorphosis Aarseth claims as an ideology of influence from which the players' game experiences are defined. Anamorphosis, due to its hidden nature, requires a specific attention from the translators while at the same time they have to consider GILT (Globalization, Internationalization, Localization, and Translation) and translation strategies that could bridge the two considerations. The problem also occurs when translation techniques are applied. Translation techniques are taken as a consideration not only for their purposes to transfer meaning but also for their possibility to consume extra spaces.

\section{REFERENCES}

Aarseth, E. J. 1997. Cybertext: perspectives on ergodic literature. Johns Hopkins University Press Baltimore, Maryland.

Bal, M. 2009. Narratology: Introduction to the theory of narrative. University of TorontoPress. Toronto.

Bernal-Merino, M. Á. 2009. Video games and children's books in translation.The Journal of Specialised Translation, 11, 234-247. London.

Bogost, I. 2007. Persuasive games: The expressive power of videogames. Massachusetts Institute of Technology (MIT). Massachusetts.

Dietz, F. 2007. " How Difficult Can That Be?"-The Work of Computer and Video Game Localization. Tradumàtica: traducció i tecnologies de la informació i la comunicació,(5). Barcelona.

Esselink, B. 2000. A practical guide to localization (Vol. 4). John Benjamins Publishing. Amsterdam. 
Fernández Costales, A. 2012. Exploring translation strategies in video game localization. Oviedo.

Frasca, G. 1999. Ludology meets narratology: Similitude and differences between (video)games and narrative. Ludology. org. Helsinki.

Frasca, G. 2007. Play the message: Play, game and videogame rhetoric.Unpublished $\mathrm{PhD}$ dissertation. IT University of Copenhagen, Denmark.

"Game." From Half-Real: A Dictionary of Video Game Theory. http://www.halfreal.net/dictionary/\#game. (Accessed October 17, 2015.)

Huizinga, J., \& Hull, R. F. C. 1949. Homo ludens. A study of the play-element in culture.[Translated by RFC Hull.]. Routledge \& Kegan Paul.Işı̆gan, A. (2013). The production of subject and space in video games. $G|A| M \mid E$ Games as Art, Media, Entertainment, 1(2).

Järvinen, A. 2002.. Gran Stylissimo: The Audiovisual Elements and Styles in Computer and Video Games. In CGDC Conf.. California.

Jayemanne, D. 2009. Generations and Game Localization. Eludamos. Journal for Computer Game Culture, 3(2), 135-147. Cambridge.

Juul, J. 2005. Half-real. Video Games between Real Rules and Fictional Worlds. Cambridge (Massachusetts) und London. Oldenburg.

Mangiron, C., \& O’Hagan, M. 2006. Game Localisation: unleashing imagination with 'restricted'translation. The Journal of Specialised Translation,6, 10-21. London.

O'Hagan, M., \& Mangiron, C. 2013. Game localization: translating for the global digital entertainment industry (Vol. 106). John Benjamins Publishing. Amsterdam.

O’Hagan, M. 2009. Putting pleasure first: localizing Japanese video games.TTR:Traduction, terminologie, rédaction, Vol 22(1), 147-165. Montréal.

Munday, J. 2008. Introducing translation studies . London and New York.

Nord, C. 2006. Loyalty and fidelity in specialized translation. Confluências: Revista de

Tradução Cientifica e Técnica, 4, 29-41. Barcelona.

Purnomo, S.L.A \& Purnama, S.L.P. 2013. Penerjemahan Video Games. IAIN Press. Surakarta.

Purnomo, S. L. A. 2015. Grab the Garb: The Influences of Translation Techniques in the

Ludological Aspects of Video Game Translation (A Case Study of Square Enix's

Lightning Returns: Final Fantasy XIII). IZUMI, 4(1), 1-9. Semarang.

Rush, J. 2005. The ergodic bridge. In MiT4: The Work of Stories. Fourth Media in Transition conference (Cambridge, MA, 6-8 May 2005). Cambridge.

Sicart, M. 2011. The ethics of computer games. Massachusetts Institute of Technology (MIT). Massachusetts.

Simons, J. 2007. Narrative, games, and theory. Game studies, 7(1), 1-21. Copenhagen.

Trifonas, P. P. 2015. Crafting the literature of semiotic possibility: from the metaphysical to

the detective story in The Name of the Rose. In International Handbook of Semiotics (pp. 239264). Springer . Amsterdam. Netherlands.

Zimmerman, E., Perron, B., \& Wolf, M. J. P. 2009. The Video Game Theory Reader 2. New York \& London. 